\title{
Design of Cooperative Operation and Profit Distribution among Principal Parts of Logistics Park
}

\author{
Shusheng Sun ${ }^{a}$, Huidong Zhou ${ }^{b}$ \\ School of Management, Wuhan University of Science and Technology, Wuhan 430081, China; \\ asunshusheng@wust.edu.com, b576649864@qq.com
}

Keywords: Logistics Park, logistic coordination, RBV model, profit distribution

\begin{abstract}
In order to give full play to the intensive role of Logistics Park, a logistics park established by a leading logistics enterprise and its principal part are studied so as to realize the gain of the logistics park and its principal part through the establishment of cooperative relationship and the distribution of reasonable profit. Based on the RBV model, this paper designs the operational framework of cooperation between logistics enterprises with the aid of the operational framework and its constituent parts, aiming to match the cooperative logistics enterprises. By using the two-person game model of the cooperative game, the gain brought by the cooperation between the leading logistics enterprises and resident logistics enterprises is distributed based on Shapley value.
\end{abstract}

\section{Introduction}

The rapid development of the logistics industry has given rise to the demand for large-scale logistics centers. After fully considering the overall layout of urban planning, the government has allocated land around the major thoroughfares in the urban-rural integration zone and improved infrastructure and corresponding facilities to attract large third-party logistics enterprise to gather here so as to gain economies of scale and reduce logistics costs: The logistics park rises in response to the proper time and conditions. Logistics Park gathers a large number of third-party logistics companies as well as advanced logistics facilities together, equipping itself with strong logistics operation and service capabilities. The logistics park builders also set up a logistics park management committee to be responsible for the management and operation of the logistics park.

All of these days, domestic and foreign scholars focused on the study of the logistics park management and operation as well as the promotion of benefit. According to data from a survey conducted in the logistics cluster in Zaragoza (Spain), Liliana Rivera et al. (2016) studied the aggregation phenomenon in the logistics park by the use of structural equation model, proving that the further gathering and active collaboration of logistics enterprises in a logistics park will present a high level of collaboration and value-added services, which will have a positive impact on the enterprises in the park ${ }^{[1]}$. Battezzati et al. (2000) considered that the logistics park further promoted the benefits of aggregation because enterprise was part of a larger institution (park) that helped to make connection within and between enterprises ${ }^{[2]}$.Ou Jiangtao's research found that the long-term co-existence of regional third-party logistics enterprises will eventually lead to either competition or cooperation ${ }^{[3]}$. Ding Hui (2011) argued that in order to realize the logistics park management model based on the fourth-party logistics providers, it must have three prerequisites: a good management platform, a good cooperation mechanism and a change in the profit model of the logistics park ${ }^{[4]}$.

Through literature review, it can be found that more and more scholars applied collaborative cooperation and the fourth-party logistics model to the management and benefit improvement of logistics parks. However, the key study object is the construction management party of the park or the treatment of the relationship between the fourth-party logistics providers and many third-party logistics cluster as well as the improvement of the logistics services, which neither take into consideration the situation that in the level of logistics enterprises, the collaboration in the logistics park is established and led by a third-party logistics enterprise and cooperated with other third-party 
logistics enterprises, nor the problem of profit distribution in the process of cooperative operation. Therefore, it's necessary and far-sighted to study the cooperation between the leading logistics enterprises and the resident logistics enterprises as well as the reasonable distribution of profit targeted on a logistics park established by a dominant logistics enterprise.

\section{Characteristics of Logistics Park and Its Principal Part}

As a logistics center, logistics park attracts a large number of resident logistics enterprises according to different sources of profit, which can be divided into three categories: logistics park, the leading logistics enterprises and resident logistics enterprises. The following will make a brief analysis on its operating characteristics and sources of profit based on this classification:

(1) The Operational Characteristics of the Logistics Park

As a gathering place for third-party logistics enterprises and logistics facilities, logistics park is equipped with a strong logistics operation and service capabilities. The logistics park builders also set up a logistics park management committee to be responsible for the management and operation of the logistics park. In particular, after the introduction of the fourth-party logistics model, the logistics park management committee fully uses its integration capability of logistics resources through the establishment of fourth-party logistics providers. On the one hand, it provides customers with complete supply chain logistics solutions. On the other hand, it also provides all aspects of logistics services by entrusting third-party logistics enterprises. The park management committee obtains benefits through value-added services and creates the largest added value of logistics value in the logistics park.

(2)The Builder and Managing Party of the Logistics Park - The Leading Logistics Enterprise

With the rapid development of the third-party logistics enterprises, after the establishment of large-scale self-owned warehouses by a large number of third-party enterprises, they have given full play to their advantages of comprehensive logistics facilities, large scale and strong logistics operation ability, further negotiated with the government to obtain land and expanded into logistics park based on their own warehouses so as to attract other logistics enterprises to settled in and turned themselves into the leading logistics enterprises of the logistics park. After the introduction of the fourth-party logistics model, the simple non-cooperative principal-agent relationship between the original managing party of the logistics park and the resident logistics enterprises is no longer suitable for the relationship between the leading logistics enterprises and the resident logistics enterprises, both of which were competitive with each other in logistics business. It's particularly important for the leading logistics enterprises to deal with their relationship with the logistics enterprises.

(3) The Resident Logistics Enterprise of the Logistics Park

There's only one operation route for logistics enterprises: to undertake market logistics business. However, a logistics company cannot obtain more markets and platforms with limited resources, which also restricted its ability to integrate the supply chain and save the cost. With the help of the fourth-party logistics platform established by the leading logistics enterprises, it can participate in the resource integration of the logistics enterprises in the logistics park and takes charge of the link that can give full play to its most competitive aspects of logistics in logistics activities so as to improve the public facilities and management level in the logistics parks. They work together with each other to expand their own profit margins. At the same time, resident logistics enterprises can also gain convenience through the improvement of the public facilities and management level of the logistics park.

\section{Principal Part of Logistics Parks' Cooperation Building}

From what have been mentioned above, there's great interest relevance between the leading logistics enterprises and the resident logistics enterprises. The benefit of leading logistics enterprises was from the development of their own market business on the one hand, and from the management 
of the logistics park on the other hand. The benefits from the logistics park management and operation depended on the number of resident logistics enterprises and the range and number of logistics business in the park. The benefits of resident logistics enterprises mainly come from the business development of their own logistics market, but the management and public facilities and services provided by the logistics parks will affect the logistics service level of the resident enterprises. There's a direct and indirect relationship between the two interests.

\subsection{The Cooperation Relationship of Principal Part in the Process of Operation}

Logistics park is an intensive center for logistics services. With the help of the fourth-party logistics providers established by leading logistics enterprises, leading logistics enterprises can cooperate with resident enterprises so as to improve logistics efficiency, reduce logistics risks and give full play to the platform advantages of the leading logistics enterprises. Resident logistics enterprises can have a partnership with the leading enterprises by combining their own logistics characteristics so as to expand their business capabilities and complete the logistics business that cannot be completed on their own. The simple relationship of employer and the tenant between the leading logistics enterprises and resident logistics enterprises can neither give play to the characteristics of the logistics park as the distribution center nor satisfy the principle of the maximum profit pursued by rational economic man. After introducing the fourth-party logistics model, the leading logistics enterprises in the logistics park establishes a fourth-party logistics platform, and has a partnership with resident logistics enterprises through the logistics business collaboration so as to reduce logistics costs, increase logistics business profits of both sides as win-win cooperation. Through the cooperation of the fourth-party logistics platform, the service level of logistics park such as management and operation, public infrastructure and e-commerce platform will be enhanced to attract more resident logistics enterprises and increase the benefit of the leading logistics enterprises from the management and operation of the logistics parks. The improvement of logistics park management level and service facilities will also increase the logistics service level of resident logistics enterprises, reduce the consumption costs of logistics activities and enhance the market competitiveness of enterprises. The interest relevance of the principal part of logistics park is demonstrated in Picture 1:

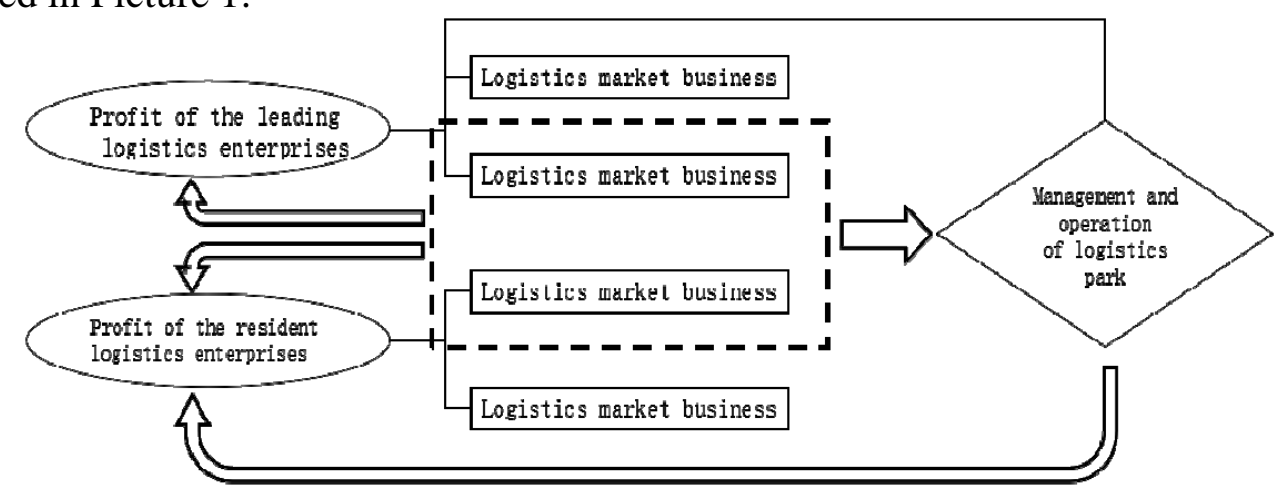

Picture 1 The interest. rel evance of the principal part. of logistics park

\subsection{Principal Part of the Fourth-Party Logistics’ Cooperation Building}

In the research of Barney in 1996 and his ongoing research, taking the enterprise resources as the starting point, he analyzed enterprise resources that can be integrated and collaborated, such as assets, capabilities, processes, knowledge, and information. In order to enhance the competitive advantage of the enterprise, he put forward a resource list (RBV, the resource-based view) ${ }^{[5]}$ that can be used for integration by enterprise. This classification was also widely used in the field of logistics to solve the problem of resource integration in the supply chain. In 2010, on the basis of this, Wu et al. combined extensive literature research to classify the resources of industrial clusters and concluded that the cooperative capabilities of enterprises can be divided into six major elements: logistics collaboration, cooperative expansion, financial capability, innovation capability, business cooperation and logistics flexibility ${ }^{[6]}$. This article will follow the classification of the six major elements, and in the context of the fourth-party logistics, improve the cooperation framework 
between the leading logistics enterprises and the resident logistics enterprises in combination with the actual operation situation of the logistics park.

(1) Logistics Collaboration

Logistics collaboration refers to the resources, data and information involved in sharing cooperation during the collaboration process of logistics enterprises. Different logistics enterprises will adopt different management mechanisms to reduce logistics costs or improve logistics service levels. A joint management of inventory logistics enterprise, working together with JIT enterprises, should achieve the synchronization of logistics information. Through the sharing of logistics information, logistics operation information can be ensured the timely delivery so that the cooperative enterprises can make timely feedback on the logistics operation process and adjust the logistics operation program according to the customer's logistics expectations.

(2) Cooperative Expansion

The fourth-party logistics integrates the resources of the leading logistics enterprises and the resident logistics enterprises so as to reduce logistics costs to the maximum extent under the premise of meeting the customer's logistics requirements. Through the logistics enterprises with needs complementary to their own business features, the shortages of logistics transportation can be complemented by the use of the resources of the cooperative logistics enterprise to collaborate with each other so that the costs of the logistics process can be controlled all the way and the logistics services can be provided at the lowest cost. Leading logistics enterprises can cooperate with the resident enterprises so as to give full play of the advantages of leading logistics enterprises platform. Resident logistics enterprises can have a partnership with the leading enterprises by combining their own logistics characteristics so as to expand their business capabilities and complete the logistics business that cannot be completed on their own. The extension of business capability will gain more advantages in the competition of logistics industry.

(3) Financial Capability

The sharing of information has been strengthened during the cooperation of enterprises. As a result, cooperation enables more innovation, optimizes logistics and adjusts logistics structure, which will enhance its management capital and capabilities. Analysis on new business aims to avoid wasting time and cash, and financial support from the outside is also needed so as to simplify the operation of the business. The financial capability of an enterprise can be judged by its business dealings with banks to see if it meets the needs of cooperation. Only with the establishment of a good credit relationship with banks as well as the qualifications and conditions of the loan of the enterprise itself can the loans be acquired in time to solve the financial problems of logistics operation in the process of cooperation.

(4) Logistics Flexibility

A key aspect of the effectiveness of cooperation is flexibility. The flexibility of logistics activities is related to the logistics operation system and the logistics resources involved and so on. Under a flexible circumstance, it helps both partners to grow rapidly by responding to customer requirements and designing logistics solutions at appropriate cost. A complete solution will be handed over to the e-commerce platform, logistics operation departments, etc. after being designed, so as to provide feedback information, shorten the time of the core links of logistics program and further improve the logistics efficiency. As shown in Table 1:

\section{The Profit Distribution of Principal Part of the Logistics Park under the Fourth-Party Logistics}

In the logistics park, there is a game relationship between the leading logistics enterprises and the resident logistics enterprises: They both take the logistics business of the supply chain as the main business profit, and regard the logistics park as an important part. The profit of both sides is closely related. The problem of profit distribution after the cooperation will be an important issue for both sides. Based on the idea of Shapley value in the cooperative game, this paper rationally allocates the increased profits of the cooperation of both sides. 


\subsection{The Basic Solution to the Profit Distribution}

When participants can get more benefits through cooperation than in the non-cooperative state, it can be called cooperative game. In cooperative game, the solution to the profit distribution can be divided into two situations. The two-person game is one of them, also known as the two-person bargaining problems, which Nash bargaining equilibrium solution is generally adopted. ${ }^{[7]}$ The other is the coalition game, which Shapley value solution is generally adopted ${ }^{[8]}$. The coalition game is also applied in the profit distribution of supply chain in domestic. In the problem of profit distribution of supply chain, Jiang Pengfei regarded it as a problem of two-person game between manufacturer and supplier by introducing Shapley value and K-S solution to improve and allocate the increased profits of coalition $^{[9]}$.

\subsection{The Cooperation Profit Distribution of Principal Part of Operation}

This chapter mainly studies the profit distribution after the cooperation between the leading logistics enterprises and the resident logistics enterprises. When logistics enterprises do not cooperate, they will complete their own business gained in the logistics market.

When a logistics enterprise completes a business with q number of customers, the unit cost it takes for the logistics enterprise is c, and the remuneration it receives from the client is $\varphi$, then, their profits are respectively:

$$
\begin{aligned}
\mathrm{V}_{1}\left(\mathrm{q}_{1}\right) & =\varphi\left(\mathrm{q}_{1}\right)-\mathrm{c}_{1} \mathrm{q}_{1} \\
\mathrm{~V}_{2}\left(\mathrm{q}_{2}\right) & =\varphi\left(\mathrm{q}_{2}\right)-\mathrm{c}_{2} \mathrm{q}_{2}
\end{aligned}
$$

According to the logistics business volume, the remuneration paid by customers can be divided into two parts. One part is the fixed compensation a, the other part is a variable remuneration $\varepsilon q$ based on the logistics volume. $\varepsilon$ is a variable coefficient with reference factors such as the logistics volume, risk level and quality requirements etc. In general $\varepsilon>c$. Then:

$$
\varphi(q)=\mathrm{a}+\varepsilon q
$$

Obviously, compared with the non-cooperative game, logistics costs will reduce after the cooperation, and the profits of both participants will also increase correspondingly. After the cooperation between both parties, the overall profit of both parties is as follows:

$$
\mathrm{V}_{1,2}\left(q_{1}, q_{2}\right)=\varphi\left(q_{1}+q_{2}\right)-c\left(q_{1}+q_{2}\right)
$$

$c$ is the logistics unit cost after the cooperation. As we all know, the premise of cooperation is to reduce the logistics costs and to obtain profit. Therefore, it must have: $c<\min \left\{c_{1}, c_{2}\right\}^{1 /}$

The increase of profit can be measured by its contribution to the overall cooperation, which must be accepted by both parties and the logistics operation process will also be protected. The added profit of the coalition is:

$$
\Delta \mathrm{V}=V_{1,2}-V_{1}-V_{2}=\left(c_{1}-c\right) q_{1}+\left(c_{2}-c\right) q_{2}
$$

From (1) we can see $\Delta \mathrm{V}>0$. At this point, the increase of the coalition profit by the join of leading logistics enterprises and resident logistics enterprises, namely the Shapley value is respectively:

$$
\begin{aligned}
& \Delta \mathrm{V}_{1}=V_{1,2}-V_{1}=a_{2}+\varepsilon q_{2}-c\left(q_{1}+q_{2}\right)+c_{1} q_{1} \\
& \Delta \mathrm{V}_{2}=V_{1,2}-V_{2}=a_{1}+\varepsilon q_{1}-c\left(q_{1}+q_{2}\right)+c_{2} q_{2}
\end{aligned}
$$

According to proportionality coefficient: $\mathrm{k}=\frac{\Delta \mathrm{V}_{1}}{\Delta \mathrm{V}_{2}}$, the overall profit of cooperation should be allocated, which the profit distribution solution can be obtained:

$$
\begin{aligned}
& \mathrm{V}_{1}^{\prime}=\mathrm{V}_{1}+\frac{\Delta \mathrm{V}_{1}}{\Delta \mathrm{V}_{1}+\Delta \mathrm{V}_{2}} \cdot \Delta \mathrm{V}=a_{1}+\varepsilon \mathrm{q}_{1}-\mathrm{c}_{1} \mathrm{q}_{1}+\frac{\Delta \mathrm{V}_{1}}{\Delta \mathrm{V}_{1}+\Delta \mathrm{V}_{2}} \cdot \Delta \mathrm{V} \\
& \mathrm{V}_{2}^{\prime}=\mathrm{V}_{2}+\frac{\Delta \mathrm{V}_{2}}{\Delta \mathrm{V}_{1}+\Delta \mathrm{V}_{2}} \cdot \Delta \mathrm{V}=a_{2}+\varepsilon \mathrm{q}_{2}-\mathrm{c}_{2} \mathrm{q}_{2}+\frac{\Delta \mathrm{V}_{2}}{\Delta \mathrm{V}_{1}+\Delta \mathrm{V}_{2}} \bullet \Delta \mathrm{V}
\end{aligned}
$$

Compared with the non-cooperative state, the profit of the two parties has increased, and can be divided into two parts: one part is the pre-cooperation profit and the other part is the profit distribution from cooperation. Through cooperation, the more profits they increase the more profits 
the two sides will gain on the basis of obtaining the original profits. The more profits they receive, the more they will encourage the cooperation partners to work harder so as to promote cooperation.

\section{Conclusion and Expectation}

Through the design of the cooperative operation and profit distribution of the leading logistics enterprises and the resident logistics enterprises, we can draw the following research conclusions and strategic suggestions: The management and operation of the logistics park based on the fourth-party logistics, give full play to the greatest role of logistics facilities in the park and strengthen the cooperation between logistics parks and logistics enterprises so as to enhance the efficiency of the logistics park. Leading logistics enterprises and resident logistics enterprises can proceed from their own resources, compared the six elements of cooperation and its composition so as to match the logistics enterprise with business expertise and be able to complement their own shortages, resulting in cooperation and increase of profit. The premise of cooperation between logistics enterprises is that through cooperation, they will be able to optimize logistics solutions and reduce logistics costs, which will ultimately be reflected in the increase in profit. The profit distribution directly affects the stability of cooperation and the quality of service. The profit distribution based on Shapley value, on the one hand, takes into account the influence of the partners on the overall profit. On the other hand, the profit distribution issue is also more reasonable and feasible without influencing the profit of the partners before the cooperation. The research of this paper is to obtain the profit of both partners through the cooperation by reducing the logistics cost, and to allocate the profit correspondingly without considering whether the cooperation has any impact on other factors. The cooperation between logistics enterprises as well as the change of the profit caused by the influence of logistics operation costs, logistics and operational risks, the efforts of both parties and other factors will be our next goal.

\section{References}

[1] Rivera L, Sheffi Y, Knoppen D. Logistics clusters: The impact of further agglomeration, training and firm size on collaboration and value added services[J]. International Journal of Production Economics, 2016, 179:285-294.

[2] L. Battezzati, R. MagnaniSupply chains for FMCG and industrial products in Italy: Practices and the advantages of postponement Int. J. Phys. Distrib. Logist. Manag., 30 (5) (2000), pp. 413-424.

[3] OU Jiang Tao, MA Zujun.Evolutionary Game Analysis of Co-opetition Strategy in Regional Logistics Parks [J]. Operations Management and Administration, 2016,25 (2): 98-103.

[4] Ding Hui.Study on Resource Allocation of Logistics Park Based on the Fourth Party Logistics [J] .Zhejiang University of Science and Technology, 2012.Barney, J.(1996), "The resource-based theory of the firm”, Organization Science, Vol. 7 No. 5, pp. 469-469.

[5] Wu, F., Yeniyurt, S., Kim, D. and Causgild, S.T. (2006), “The impact of information technology on supply chain capabilities and firm performance: a resource-based view”, Industrial Marketing Management, Vol. 35 No. 4, pp. 493-504.

[6] John Nash, Two Person Cooperative Games[J],18(1950);128-140.

[7] Shapley. A value for n-person games[J]. in Kuhn and Tucker editors, Contributions tothe Theory of Games. 1953,volume 2 of Annals of Mathematics Studies,28.Princeton University Press:307-317.

[8] Jiang Pengfei. Cooperative game solution and its application [D] .Shandong University, 2007. 